\section{Making news}

SIR - In his article on possible triggering of solar oscillations by gravitational waves (Nature 20 October, p.665), Robert Walgate implicitly raises the question of journalistic sensationalism when dealing with scientific questions. Concerning the Le Monde headline which he quotes, I asked for a cautious title, or at least the insertion of a question mark as in Walgate's article, obviously without success. Walgate goes on to make an error that I wish to correct. A journalist ought to know that it is impossible for anyone to show a proof of the front page of a Parisian evening newspaper in Frascati several hours before publication. Moreover it would have been absolutely ridiculous for any scientist to do so.

I did show, however, two pieces of information that were not available in the scientific literature when they were published in newspapers and which really did play an important role in our research. One dealt with the identification of the optical counterpart of Geminga and its astrophysical consequences (Le Monde 24

IMAGE
UNAVAILABLE
FOR
COPYRIGHT
REASONS

Hold the front page - Le Monde of 12 October

August 1983) and the other was an Italian headline announcing in late September the 12-sidereal-hour periodicity found by Amaldi and his group with their gravitational wave detectors. Before Walgate's article this was, to my knowledge, the only published material on this subject.

Putting aside the irritating sensationalism over which scientists have little control, let us turn to this more interesting point: quick release of new results already known to specialists through meetings or the circulation of preprints. Those working within a restricted field know what will be in print six months or a year later so a research worker coming from outside the field has to start with second-hand information. A good example may be found in Gough's excellent review of the 1983 Catania meeting in which Isaak's specu- lation on gravitational waves and Kotov's claim about earthquakes are reported (Nature 304, 689; 1983). Thanks to Gough and Nature's speed, someone specializing in Geminga or gravitational waves could have found there a glimpse of the idea that led us to search for periodicity in Geminga, not needing to rely entirely on newspapers for quick scientific release.

This was the only message that I wanted to convey when I held up a cutting from an inside page of an old copy of Le Monde.

Universite de Nice, Philippe Delache

Observatoire, BP252 06007 ,

Nice Cedex, France

\section{AIDS funding}

SIR - In your leading article "Money for AIDS" (Nature 25 August, p.671) you ask . . . "Will the money be well spent or are all the haste and dollars a recipe for much poor research, an easy ride on the bandwagon?" You continue. . . "There is a temptation to compare these events with the great drive against cancer initiated by President Richard Nixon in the early 1970s. As some predicted and as many concluded, the huge sums of money made available through the National Cancer Institute (NCI) bought a lot of poor research, and on the whole, poor returns."' I do not quarrel with the prediction, but the statement "as some predicted and as many concluded" is in my opinion a sweeping statement for which the evidence is at best anecdotal. I know of no place where the conclusion was drawn that the huge sums "bought a lot of poor research, and on the whole, poor returns". In fact I think it bought a lot of good research and the returns were substantial. Perhaps I am biased. I was a senior official in NCI during this period and played some role, largely intramural, some external in the allocation of the money made available to NCI.

The next thing is that the drive was not initiated by President Nixon; it originated from a panel of consultants on the "Conquest of Cancer", which was a consultative body appointed by a Senate committee. It was also known as the Yarborough Committee. I am not certain where Senator Yarborough derived the idea of creating such a panel, but the recommendations of the panel led to increased appropriations for cancer. I think it would help if you would read the statements that Mr Nixon made at the time he signed the act. He understood as well as the scientists what could be achieved.

I find it difficult to accept that an editorial in Nature could continue to repeat charges that really have no substance, but more particularly that the conclusions about whether the research that was done was good and the returns poor are without grounds other than opinion.

NATHANIEL I. BERLIN Cancer Centre, Northwestern University, Chicago, Illinois 60611, USA

\section{Indian institute idea}

$\mathrm{SiR}$ - We share the concern of scientists in India about the plans of the Indian Government to build a "technology city" for Indian scientists trained abroad at a reported cost of $\$ 125$ million (Nature 29 September, p.350). We suggest that the money be used, instead, for building a new institution for biochemicals and "biotechnicals",

First, this institution would supply India's scientists with these materials. This may be accomplished as follows:

(1) By regularly assessing the needs of scientists all over the country in order to prepare a list of all biochemicals and biotechnicals needed.

(2) By meeting these needs either by manufacturing the required materials or by importing them from abroad.

(3) By providing or making arrangements to provide from a supplier whatever biochemicals, immunochemicals, radiochemicals or biotechnicals are needed within 24 hours of a request from any part of the country. If necessary, a special postal service for scientific supplies could be created.

A second important function of the proposed institution would be to conduct workshops and short courses in specialized areas to give further training to scientists and technicians from other institutions in the country. Faculty for such workshops should be drawn from all over the world.

We further suggest that the proposed institution be built in the city which the government of India may offer as a site for the UN biotechnology centre. Perhaps that will meet the criticism of the UN expert committee that India lacks the scientific infrastructure required by a UN biotechnology centre (Nature 29 September, p.350).

BEERELLI SESHI

SUHAS H. PHADNIS

N. SHAMALA

Washington University School of Medicine,

St Louis, Missouri 63110, USA

\section{The Yogi in Nature}

SIR - Happy though I am that you should publish Mr E.J. Zuiderwijk's letter (Nature 27 October p.758), I trust you will not be influenced by his opinions. Whether the Maharishi Mahesh Yogi is, as he suggests, a clown remains for me a matter of conjecture; I have never met the Maharishi. Like your correspondent I find some of the Maharishi's pub́lished views difficult to reconcile with my own. I also recognize an editor's perogative to publish or withhold. I most strongly reject, however, the philosophy that leads Mr Zuiderwijk to advocate denying access to your columns. Suppression is an ugly word. You are after all, Sir, the Editor of Nature, not Pravda.

N.H. KEIR

3 Hawkesbury Close, Hartburn, Cleveland, UK 